\title{
DATABASES AND COMPLEXITY. REMOTE USE OF THE DATA IN THE VIRTUAL SPACE OF RELIABLE 3D MODELS
}

\author{
Sandro Parrinello', Francesca Picchio² \\ 1,2 DICAR, Department of Civil Engineering and Architecture, University of Pavia \\ 1Sandro.parrinello@unipv.it, 2Francesca.picchio@unipv.it
}

\begin{abstract}
With the advent of digital technology, communication has undergone radical transformation processes. The large amount of information that surrounds us with sociological, cultural and economic aspects, have changed the relationship between the perceiver and the context. The perceiver takes part of space, surrounding it, finding new ways to understand it and new archive systems of the information he may acquire.

Through digital survey and the use of skilled software, the elements and the relationships of the contemporaneity become networked and accessible to the public. The database in which all the data acquired is collected, permits an extraction of useful information for the orientation in space. This possibility allows the understanding of the relationship between elements and an ever-growing conscious approach to the project. Through digitization, the virtual environment can be preserved. This paper describes an innovative methodology that links the complexity of the databases (for the management of urban and architectural systems) with representation systems and three-dimensional space archives. Some experimental researches conducted explain ways in which one can create virtual databases. These instruments can become narrative path systems where the user can find and interface with the elements of space, in a more conscious, critical and structured approach.
\end{abstract}

\begin{abstract}
Keywords
Digital database, digital survey, 3D models, virtual reality, interactive space, fruition.
\end{abstract}

\section{The databases of digital architectural survey, quality and development systems ${ }^{1}$ \\ Dealing with databases for architectural documenta-} tion is not just determining the structure of a large data system about a surrounding context, but concerns, more specifically, a new image of the place. Thanks to the understanding of the critical structure of the Database it is possible to understand the architecture of the landscape and the surrounding space. Eventhough a few years ago databases were originally a support of the architectural drawings and occupied towering bookshelves in the offices of public administration, today, as they can be considered as critical base for the understanding of the context's structure, have changed their image becoming databases, thus containers of containers.

Technological progress and the arrival of the digital Era have moved, in the area of cultural heritage, all forms of documentation systems towards the realization of digital platforms which collect descriptive systems that are useful for the development of new methodological systems for

\footnotetext{
${ }^{1}$ The first, the second paragraphs and the conclusion are due to Sandro Parrinello. The third and fourth paragraphs are due to Francesca Picchio
}

the comparison of heterogeneous information. Similarly, the science of architectural survey in all its different forms: from archaeological survey up to the urban one; has been oriented towards the development of methodologies which, through the use of laser scanning instruments and cheaper cameras, is able to produce a point cloud, or databases of spatial coordinate and vector. The result of this transposition of data, from "sign" to a "code", results in the transformation of all the processed digital graphics in a data bank, which needs to be further processed and organized in order to be managed for its maintenance.

The possibility to extend architectural dimension in the digital space, creating three-dimensional models that could be used as real spaces, is the basis upon which video games and virtual simulations, since the early $80 \mathrm{~s}$, have been developed. What is happening today is the discovery of a new virtualization process, that has involved the metric and geometric availability of the digital data, and has begun to build evermore digital archives of our architectural heritage, in the hopes of preserving their memory. Digital space (a virtual control space, known as measured and digitally expressed according to preordered mental schemes that define the 


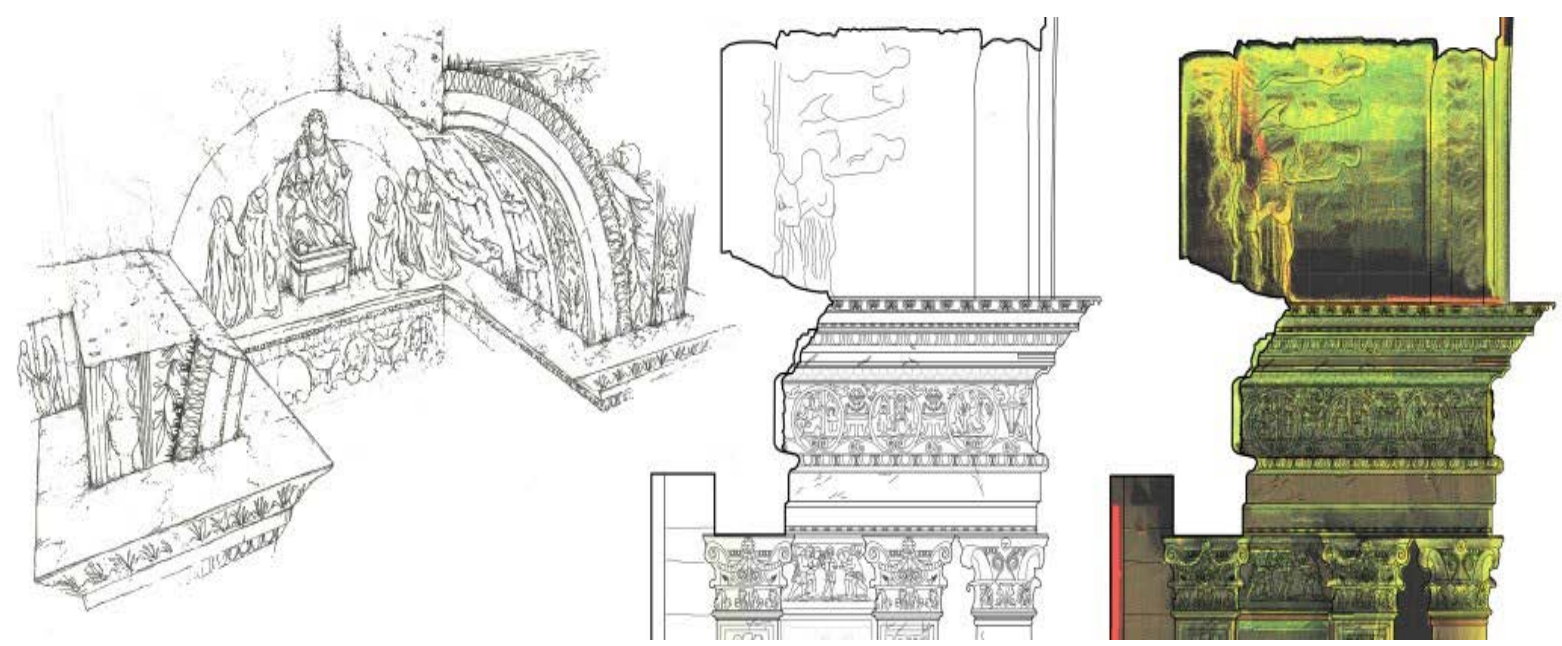

Figure 1. Perspective drawings, sections, and point cloud of the central portal of the Certosa of Pavia's facade. The evolution in representation: from the two-dimensional drawing to the display of a 3D database that consists of millions of points whose image reproduces the drawing of the architectural elements. Image from the Survey Laboratory of Prof. S. Parrinello, Civil Engineering and Architecture, University of Pavia

border and the limits of the context) becomes intelligible through the conformation of the point cloud where every single piece of the surface loses value if decontextualized, but in the context of the point cloud becomes increasingly valuable for the description of the specific space, the complete site and the mutual relations of its elements.

In particular, these point clouds are constituted of dynamic formats, in which the spatiality is repurposed in its three dimensions: the interaction with the virtual space allows a constantly changing management of the point of view and a direct interaction with the space, with the object or with the individual element, improving therefore, the knowledge of space itself.

This graphic post-production process started some years ago as a consequence of the process that transforms the drawing into a spectacular computing scene, reaches its maximum programmatic expression with the awareness of an interaction between databases. The measurement database, obtained by a practical action on the site, is based on an automatic points census acquired by laser instrumentation or photogrammetric procedures, and is regarded as the new starting point from which it is possible to conduct renewed interpretation to develop the drawing. This critical interpretation process of data acquires again the sense of a real database when it works in terms of interactions within the virtual-digital system.

The optimization procedure of digital models and the export of databases in different formats, which allow the post-production of data, revolutionizes the relationship with the artistic world, places and heritage, and contributes towards a new trust in digital technology, that must be justified, at least through the definition of standardized methodological protocols and certifications, to ensure its validity.
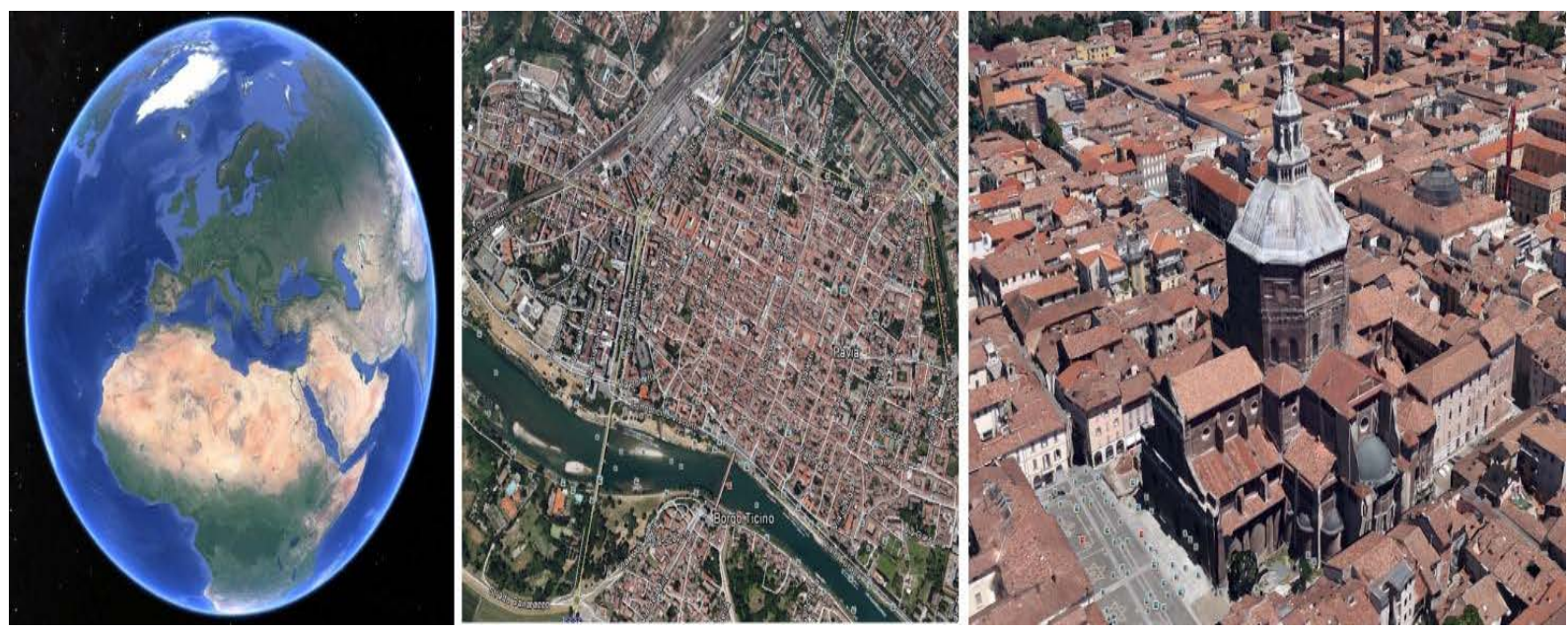

Figure 2. Google Earth is the most dynamic database used to understand geography, space, the quality of places and the structure of more complex buildings. Photographs become a model linking the images to other hypertext 

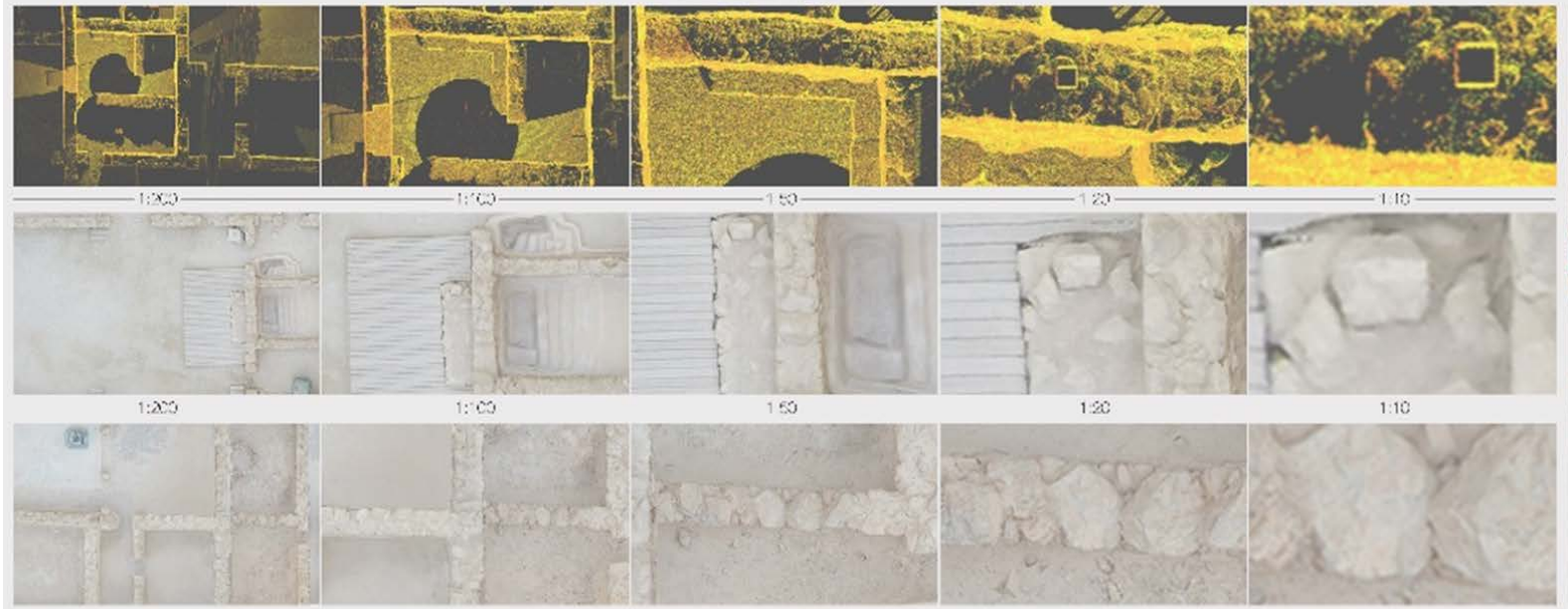

Figure 3. Point clouds obtained by laser scanner survey and photogrammetric survey compared in relation to the different graphic representation scales. It allows to check the data readability in a portion of the archaeological site at Masada (Israel)
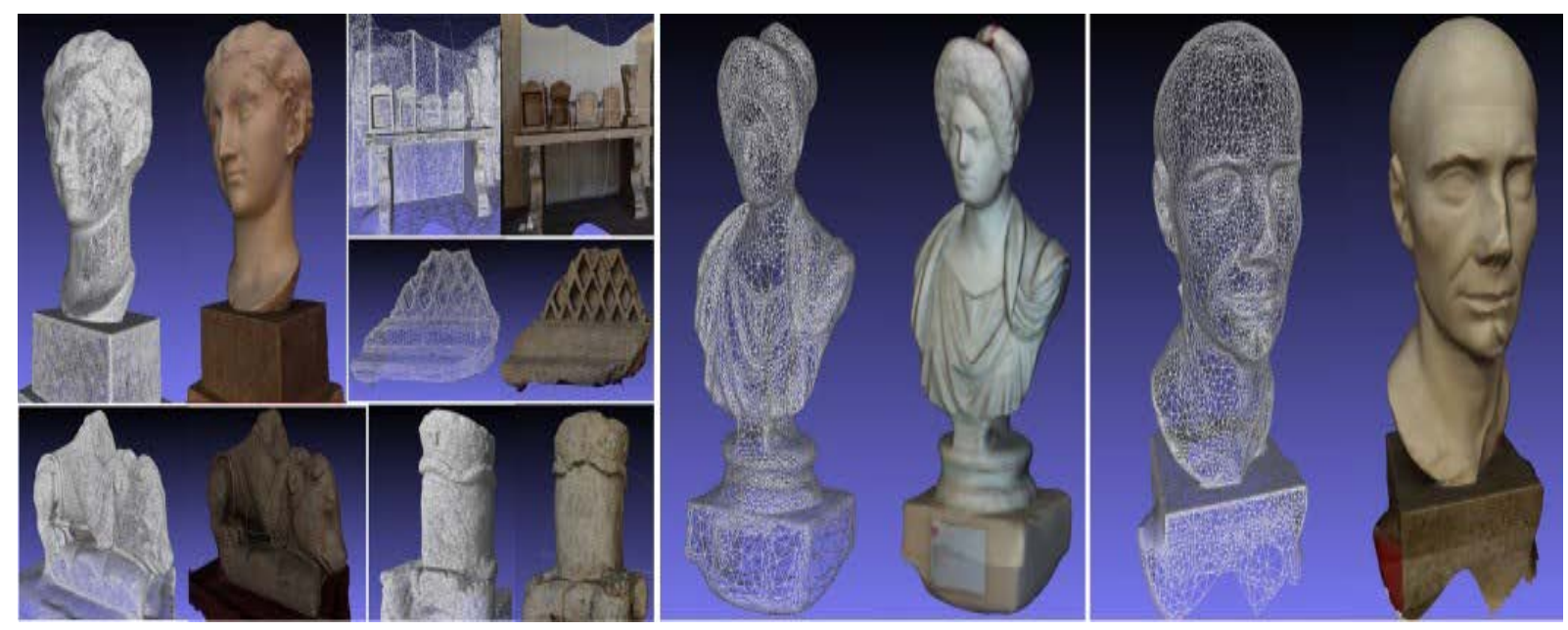

Figure 4. Digital Invasions with 3D processing of large sculptures of Salinas of the project "3D \#Digitallnvasions: a crowdsourcing project for mobile user generated content", is one example of heritage digitization and structuring of digital database that use three-dimensional data to become containers of information

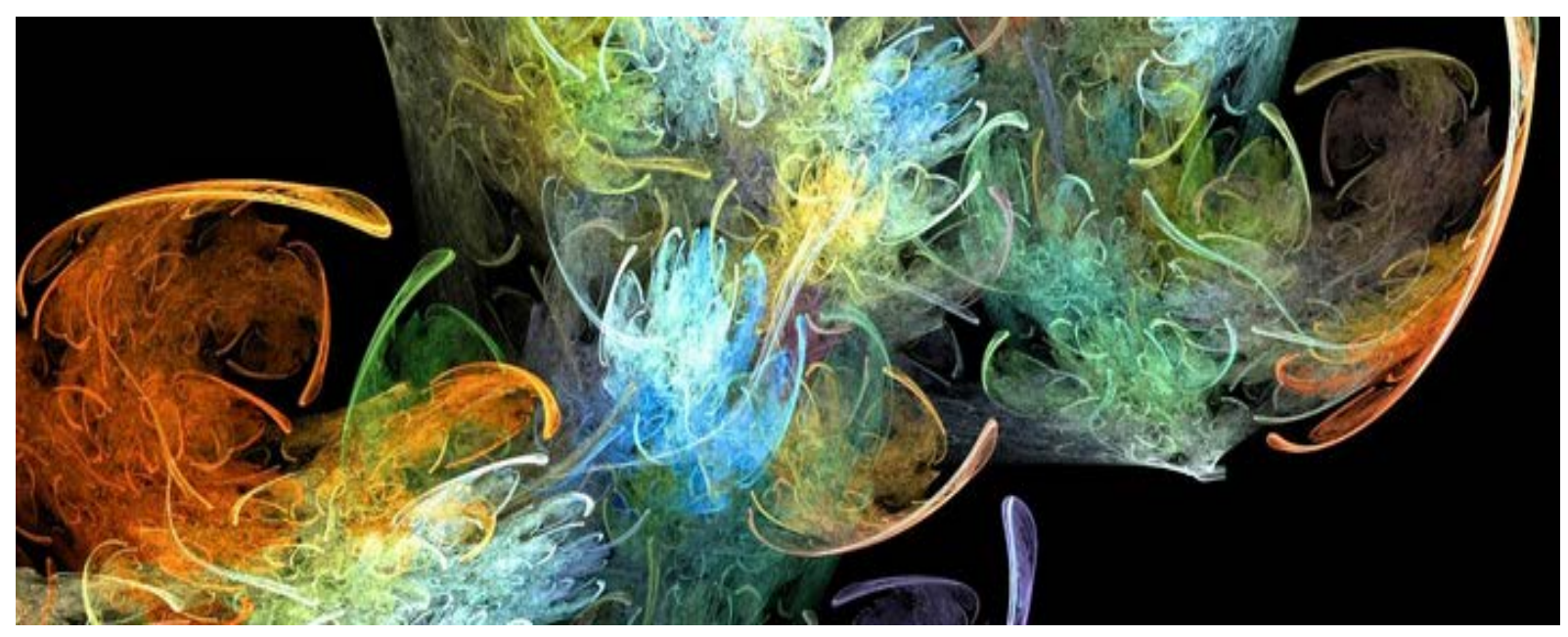

Figure 5. When coming into contact with the awareness of a cultural asset, the visible structure of the phenomenon breaks up in manifold parts, just as an ink drop getting into contact with water 
It is important to stress that, potentially, the interactions between different databases are strongly constrained to the lack of ability of programmers in the management and intervention in problems regarding the nature of files and their interactions. Under this perspective, the ability to create effective relationships between information systems and representative tools for the cultural heritage undoubtedly impacts the capability of a certain community to be "reflective", to better interpret and understand itself and, thus shaping its future, on the basis of fresher and updated data.

In particular, digital databases for cultural assets are the means necessary to structure models able to reproduce the complexity of reality, since they can provide tools for virtual simulation and connection among ambients and contexts, even when they are hugely different from one another.

In the same way, the digital databases now available, are characterized by the necessity to interact with the numerous areas of documentation, description, control and simulation of the real system.

In the recent years the increase of databases regarding cultural assets has marked the creation of numerous libraries and archiving systems, doomed to disappear because of the fast evolution of the state of art of technologies.

A crucial starting point for a significant reflection on such situation is the research implied by the architecture, where databases have to assume complex forms, supporting three-dimensional nature, and interact with data and information of different kinds, including representation systems of space.

As a consequence, the issues to tackle are both: linguistic/cultural, where the grammatical structure not only involves the lexical communication but also defines the forms for the representation models, i.e. the cognitive structures relating to both the real and the virtual systems of the databases; and technological, where the IT, the web-graphic, the design and different engineering solutions used to communicate shall find a proper way to interact in order to unify languages having digital nature.

Complexity and big data management, structuring of data for the interactive use

The revolution which began with the Digital Era has translated the whole representation sphere towards an immaterial communication system, able to propose an idealized future or a glorious past, as a witness of landscapes in transformation. To the possible utopian images that a place can assume, the research is extended to the possibility of virtually representing the complexity of contemporary urban spaces. Within our cities there are various aspects, relations - tangible and intangible - that need to be understood, captured and repurposed in a new expressive form understandable to a large and different audience. Deducing the shape and quality of the space, which consists of signs, constraints and interconnections, is the first operation that simplifies the real space and prepares the basis for the acquisition of data and its management in a virtual environment. The organization of the acquired data will allow the selection of information according to the needs of its user, to implement aspects related to the state of conservation of the architectural heritage, analyze the spatial relationships, and properly handle the post-production phases data.
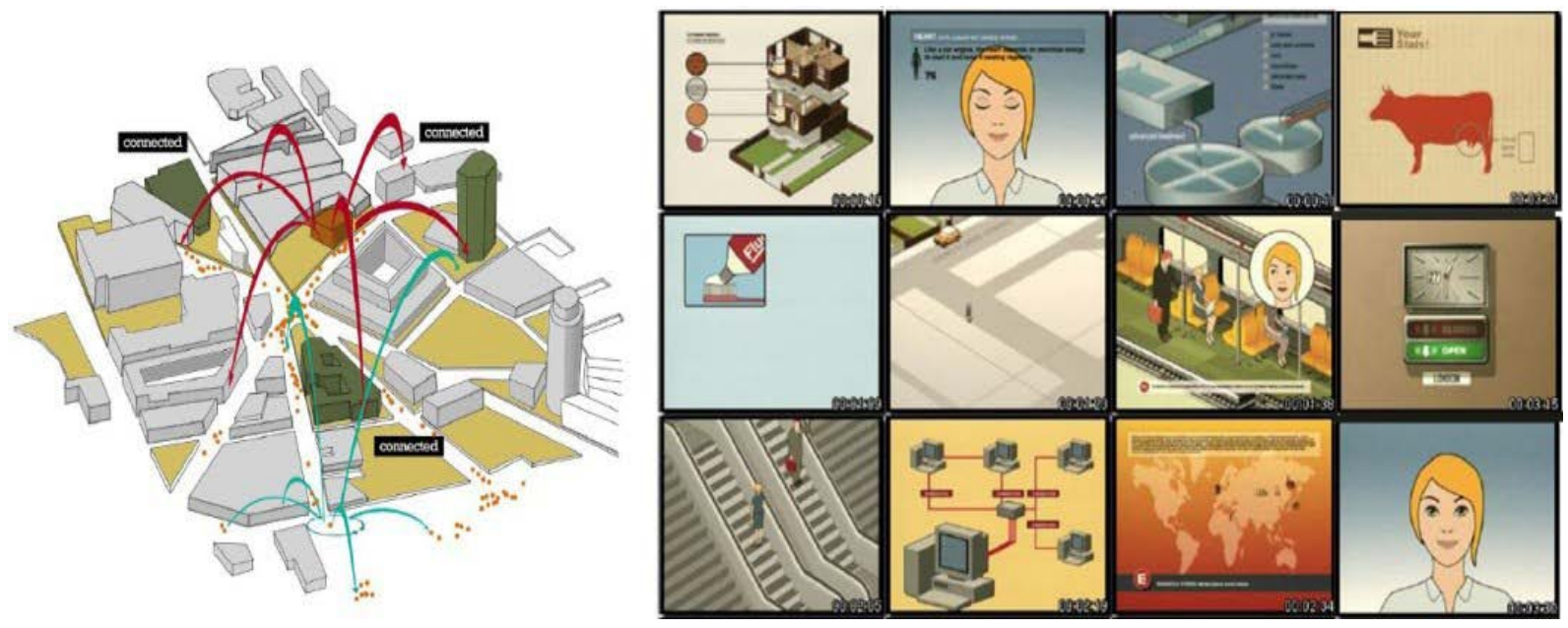

Figure 6. Some images from the video "Remind Me" of the Norwegian group Röyksopp, 2002 allude to an interconnected landscape, including buildings, streams of people and the system of communication between them; each element of the city is part of a constructive process managed in a database 

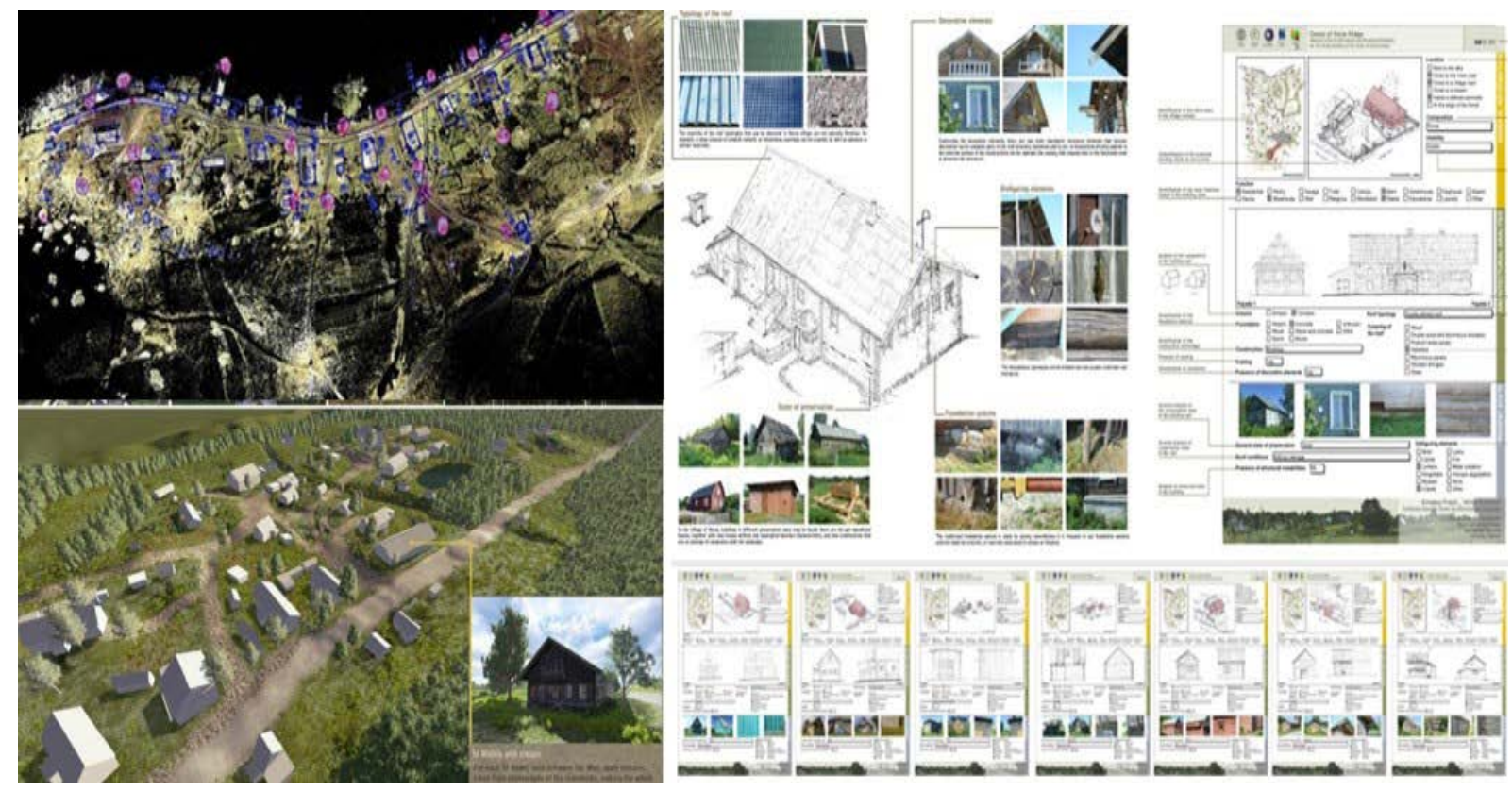

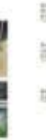

Figure 7. Database of traditional wooden villages in Karelia: census of buildings and realization of functional three-dimensional virtual system for the consultation of the material produced

The database on the urban landscape, which is constituted by the application of digital instruments, has the characteristic of being extremely reliable in metric and qualitative information aspects. Although the amount of information is overabundant they need to propose the three dimensional space in the virtual environment, the system of digital database is an open archive system, interactive and usable, which will produce an increasing data aggregation in the future to define synthesis procedure for the representation of the city.

This applied research, which today arrives to consider the synthesis and to define development models for the future, began in 2001 with the development of census systems for the analysis of the historical center of Montepulciano (SI). In the last fifteen years many researches have been conducted to be able to define the interaction systems in order to improve relations between the user and the virtual city. These researches focused on the study of the complexity in the architectural representation, in the methods of survey, and especially, on the systems of interaction between the user and the represented data.

Innovation of the scientific project, the smart cities through the database

There are numerous data banks generation experiences for the organization of the historical architectural heritage, the line of research presented in the present paper draws its strength from a multitude of experiments conducted to define a methodology for the creation of digital archives, initially, and for the development of functional and narrative systems to the use of the databases, eventually.
Moreover digital archives, especially if they present complexity, must be conceived and organized, whether they are dealing with three-dimensional metric data or with the description of the structural characteristics of a urban or a monumental system.

Experiences such as activities conducted for the census of wooden villages in Karelia, or projects for the definition of database on Italian small historical centers, up until participation for the protection of the historical landscape of Jerusalem, have allowed to determine census schedules for different purposes based on the interrelation of analytical descriptors associated with a discretization of the architectural space. Research on systems of documentation and digitization of the wooden heritage in Karelia (RF) is part of the European Research Project entitled Wooden Architecture. Traditional Karelian Timber and Landscape Architecture developed by the Seventh Framework Programme, Marie Curie Actions, coordinated by Prof. Sandro Parrinello and foster the development of international scientific research and the increase of scientific exchanges between universities of different countries. The project involved a period of thirty six months, from 2012 to 2014, during which four universities have had the opportunity to collaborate and meet on the subject of protecting and cataloging and digitization of traditional architectures of Karelian context.

The support to urban planning activity involved the digitization of some Italian small towns, including the historic center of the Municipality of Gatteo a Mare (FC), Tavarnelle Val di Pesa (FI) and Barbianello (PV), who regarded to the realization of dy-namic databases, containers of heterogeneous information but interconnected to the general digital system. 


\section{Architecture and Engineering Volume 2 Issue 2}
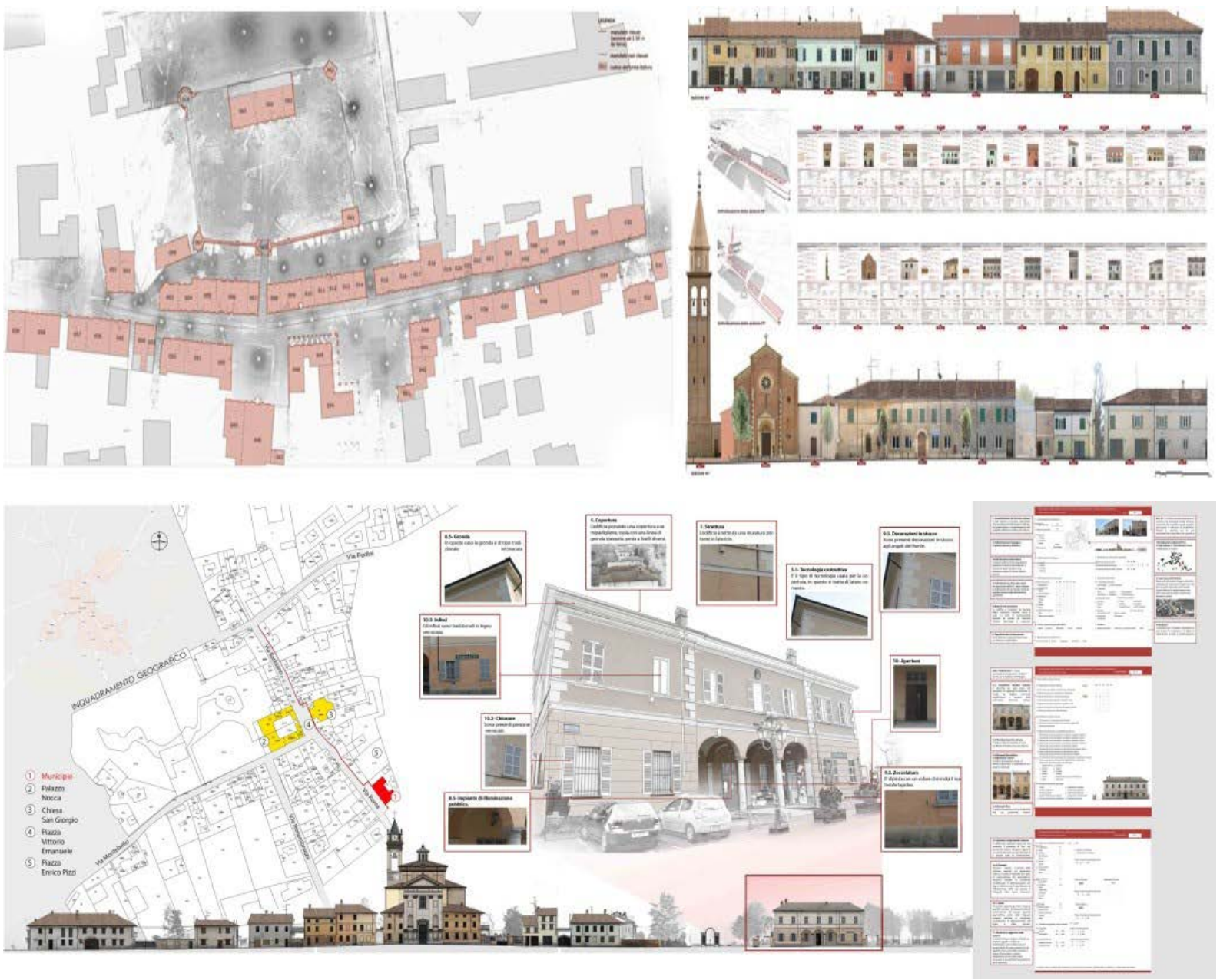

Figure 8. Databases consist of census forms drawn up for each of the buildings of an old Italian town
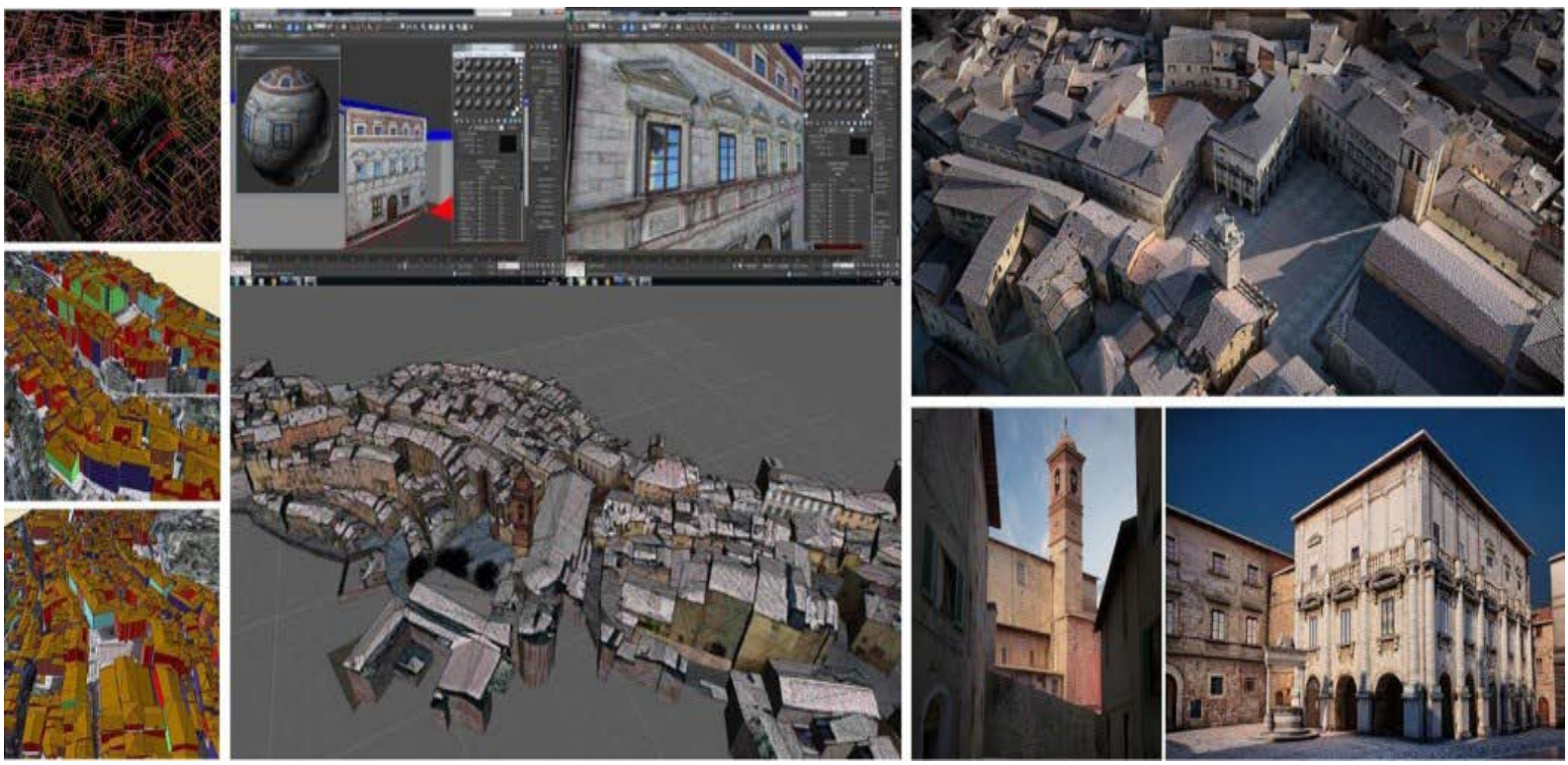

Figure 9. Image from NURBS modeling and texturing in 3D Studio Max, importing the 3D model of the town of Montepulciano($\mathrm{SI}$ ) on the interactive platform of Unity 3D. The three-dimensional system allows the total immersion user within the virtual container, which is not just a static interface of information, but a tool that, thanks to the fluid interaction of the urban fabric, allows fast access to the same content of the village. The possibilities offered by navigation are characterized by the use of visual interface and an interactive multimedia framework, which is revealed as a real emotional environment. Below some views of the model on Lumion 6.0. Project promoted by the Joint Laboratory Landscape, Survey and Design of Florence and Pavia University, coordinated by Prof. S. Bertocci and Prof. S. Parrinello. Realization of the 3D model: F. Bardini, S. Bua, F. Picchio 
The PURE project (Productivity and Urban Renewal in East Jerusalem), promoted by the European Union, by IDS Islamic Development Bank, UNDP United Nations Development Programme, and the Joint Laboratory Landscape Survey and Design of the University of Florence and Pavia, has provided a thorough and detailed analysis and survey of the buildings in the area close to the historic walls of Jerusalem town, the creation of a digital database, metrically and qualitatively reliable and elaborate two-dimensional and three-dimensional graphics drawings describing the state of conservation of each architectural element in order to protect or redesign the urban image.

The possibility to combine the complex data of the metric survey to the quality of the data from the census, improves the complexity of the digital system and the possibility of use of this instrument for projects or for planning. The research line is innovative, going through complex systems that make possible to reproduce and collect the dual aspect of a city, decoding and redrawing its features for a better understanding.

\section{Communication, fruition and interaction of SFM models in real time}

The diffusion of new media and the "fluidity" of new open source systems consider the environment and the contemporary architecture not as part of a historical process, but as an "information" system, belonging to the digital area. The information systems add the topic of interactivity of the user, the concept of being "here" and "there", outside of space and time and always interconnected with the world, which has led to an epic revolution in information technology and graphical representation (Basso, 2016). The representative aspect of the models, that are three-dimensional systems with high information content, allows the pursuit of the idealized methodological approach, that combines in both popular and managerial ways, the databases census systems of surveyed objects.

The visual appearance of a three-dimensional model obtained through photogrammetric procedures, to which is applied its corresponding texture, can satisfy the first impression about the ability of some software to generate virtual systems that are very similar to the real world. However, the interaction between user and screen offered by existing navigation systems is able to amplify the interaction with structure from motion patterns thanks to which it is possible to examine the complexity of the three-dimensional surfaces represented (Marini, 2006).

Cyberspace and virtual reality, of which new three-dimensional systems of representation of space
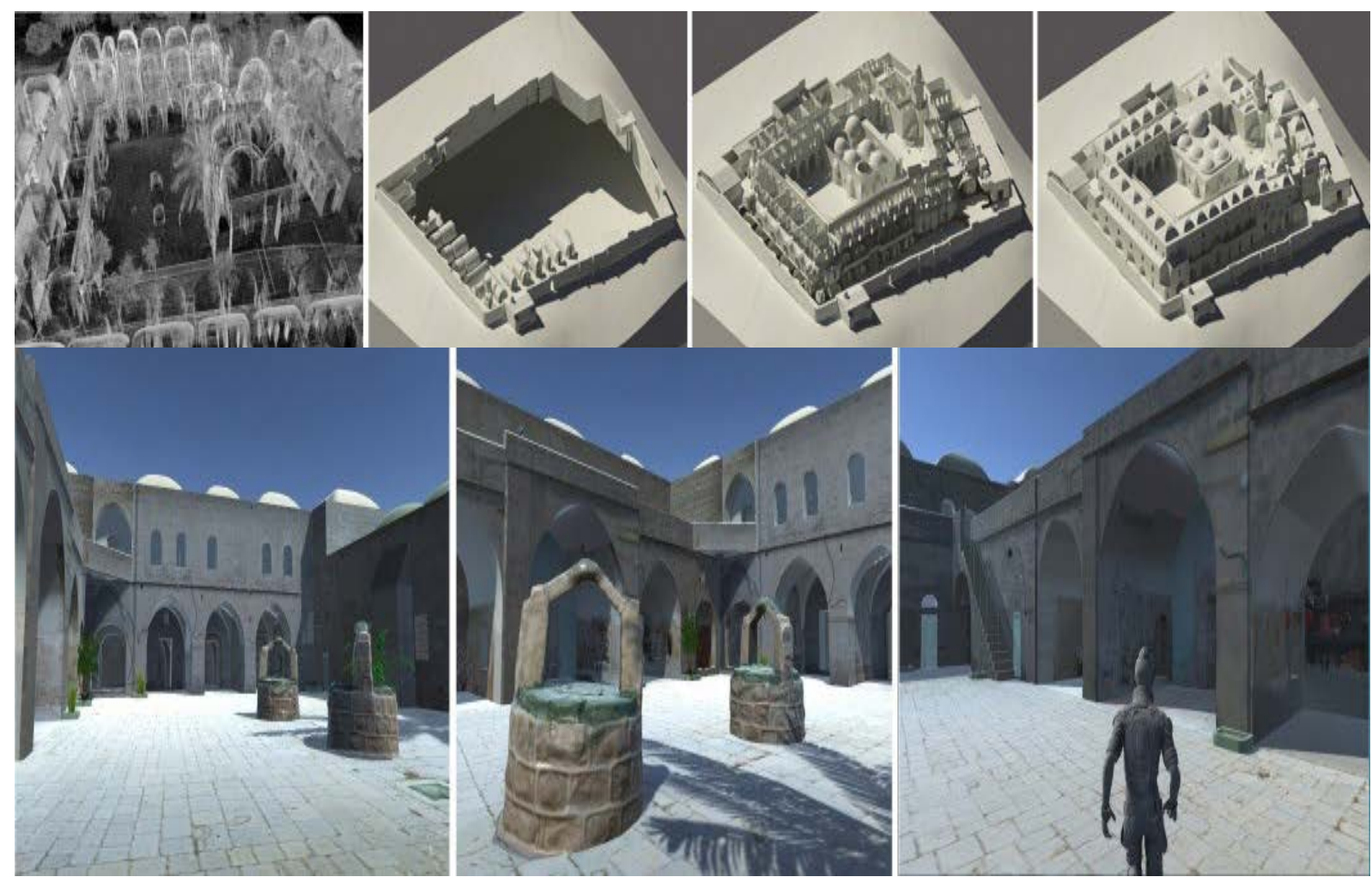

Figure 10. The realization of the three-dimensional model and the real-time model of the architectural complex of AI Nabi Musa (Palestine). The game, realized with the Unity software, is the result of a three-dimensional documentation project composed of NURBS and Mesh models, inserted within a virtual space, with the aim to digitized the complex. The operator moves freely inside the space by means of classical display or through an avatar, choosing paths and objects with which be in touch. Model made by Ph.D. stud. M. Bercigli, Department of Architecture, University of Florence 


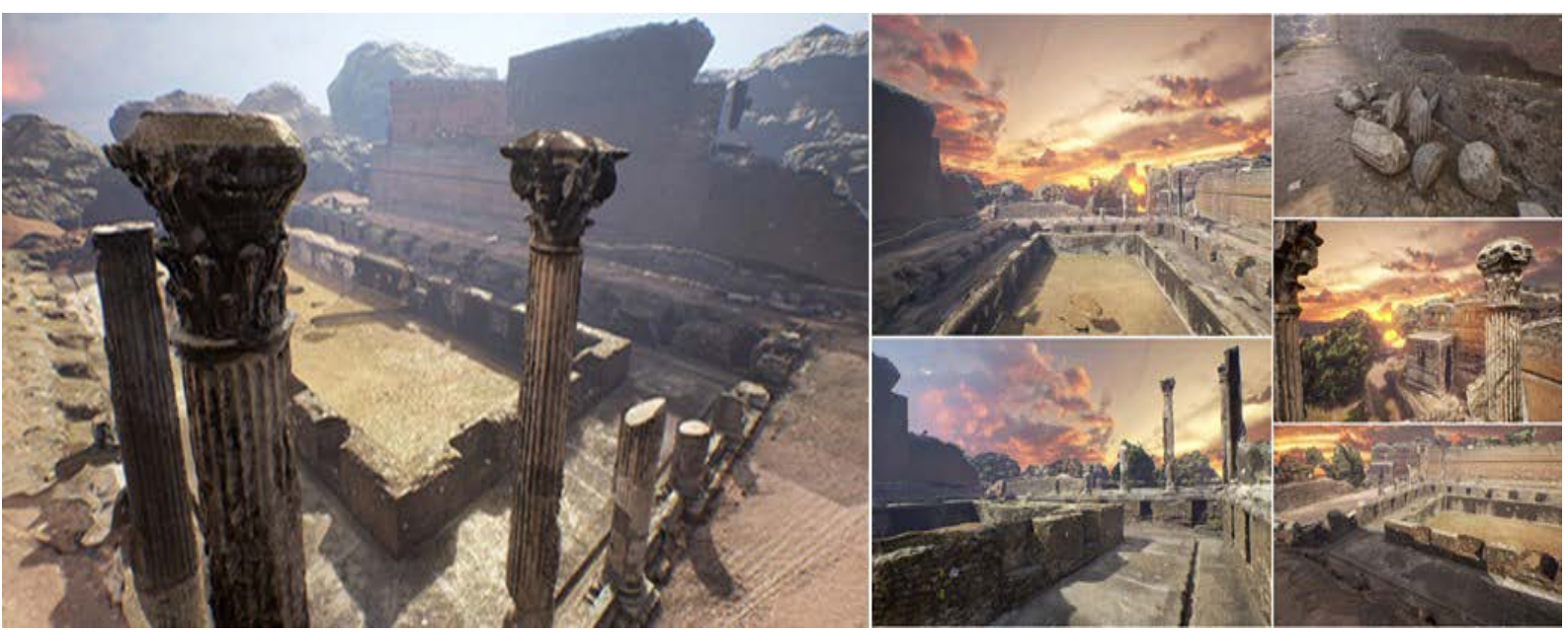

Figure 11. Portion of the building of Peschiera Villa Adriana (Tivoli). The three-dimensional model views made with the methodology structure from motion, composed entirely of mesh surfaces, imported software Unreal Engine 4. Model made by students F. Alberici, G. Chiappel-

la, G. Lentini, within the Laboratory of Prof. Relief S. Parrinello of the Degree in Civil Engineering and Architecture, University of Pavia

(including reality-based models) are a part of, allow to configure spaces, places and objects that merge various aspects of the representation from the sign to digital data, from text to sound. Thanks to the virtual reality it is possible to configure more communication purposes: from the simple digital tour of the architectural heritage, to its hypothetical reconstruction, redesign and reconfiguration.

The post-produced digital model of the virtual environment requires much attention, control and management of the data by the operator, especially in function of the aspect of the model inside the cyberspace. The structure from motion methodology, for example, takes advantage of numerical models, consisting of polygons and vertices, which approximate the shape of each architectonical element to decode 3D models. The model consists of a great number of polygons selected, under the discretion of the operator, depending on the finality of the database.

To be easily shared on a network and used, the models and the virtual places in which they are inserted must be carefully planned, in order to be easily recognized and codified.

The real time systems may offer users different levels of interaction, from those lower (as the systems created with QuickTime VR) to those with higher interaction, such as the latest generation of games, capable of mutually shared spaces and environments between various users.

The transformation from a two-dimensional to a three-dimensional system is organized on several levels of investigation, within which each element of the model, surface or single polygon can be selected and queried. This process becomes part of a methodology able to extend the use of photographic images and reality based modeling not just in management but also in the real time virtual representation.

Recent research works have involved the creation of remote runtime systems of the three-dimensional model, allowing dynamic interactions with a dense virtual space of multimedia content to help the formal material from the real space.

The dynamics of movement has an essential role in the contemporary communication system and especially in the Digital Era: the simulated object can rotate relative to the observer, and the observer can stay stationary while turning around, in a complete autonomy. Moreover, the scene can be enlarged or reduced and

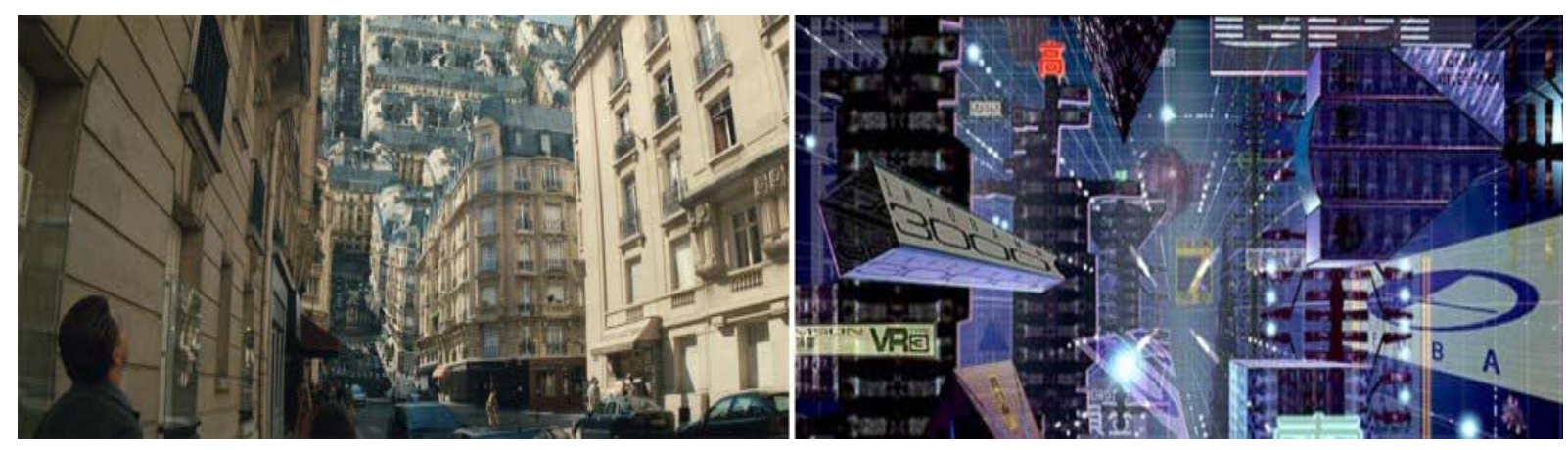

Figure 12. The digital space that looks like a city in the movie "Johnny Mnemonic" (R. Longo, 1995) and the multi-dimensional virtual reality of "Inception" (C. Nolan, 2010). Immersive systems that use databases produce more and more facilities similar to the real space in which to overcome the three dimensions to extend toward the infinity 
transformed topologically, as much as it can amplify the perceptive abilities of users. The total immersion experience within the three-dimensional space (Virtual Reality) allows the user to face, as much as he would in real life, all sensorial experiences, thus involving him in a digital space with the ability to manipulate it: the space described must consist of polygonal models that optimize the data management, to which it is possible the addition of high-quality texture to increase the perception of geometric details.

The organization of elements through a semantic procedure constitutes a fondamental organizational structure for the storage and archiving of data, as it is a consequence of the mental process of design, integrating and transforming it in a corresponding digital system, where each element can be a part of, or constitute in itself, an autonous database, complete and usable by the user.

Virtual reality appears as an effective representation of space because it allows the user to analyze, manage, and interact directly with the largest database offered by reality based models from the highly reliable detection systems, such as laser scanners and photographic instruments.

\section{Conclusion}

The advantage of the link between the databases and the models that discretize the complex area is the ability to view, learn and interact with a place in a dynamic way, within a space able to communicate heterogeneous information about its elements. The dynamic interaction joins the ability to update the digital system, through continuous interaction between the instruments used and the established database, infinitely implementable. The methodology of approach to space and database systems, census and digitization of the acquired and processed data, tries to answer to the contemporary necessity for the representation and the management of urban complexity. The drawing of the city changes from the concept of image reproduction, in two or three dimensions, to become multidimensional instruments through which the user participates, interacts and communicates constantly with the context, transforming the image depending on specific needs. This methodologically structured system is able to reformulate an updated descriptive system of spatial complexity, which is expressed through a process able of developing the digital tools as the starting point for a research on the image of the place. The virtual city, full of information, is the mirror of our civilization, through which we define the basis for the protection of heritage and develop the future aspect in which every choice will appear and seem possible within the network. 


\section{Architecture and Engineering Volume 2 Issue 2}

\section{References}

Basso, A. (2016). Analisi e riconfigurazione della città contemporanea attraverso la rappresentazione [Analysis and changing of the image of a modern city via representation]. PhD Thesis in Architecture. (in Italian)

Benedetti, B., Gaiani, M., Remondino, F. (2009). Modelli digitali 3D in archeologia: il caso di Pompei [Digital 3D models in archaeology: case study of Pompeii]. Pisa: Normale Publishing House. (in Italian)

Bertocci, S., Parrinello, S. (2007). Rilievo e Piano di Gestione per il Centro storico di Montepulciano [Geodesic map and master plan of the historic center of Montepulciano]. Florence: Alinea Publishing House, pp. 108-113. (in Italian)

Bertocci, S., Parrinello, S., Bua, S., Picchio, F. (2014). Montepulciano 3D: modelli vir 7 tuali per l'urbanistica e lo sviluppo dell'ambiente urbano [Montepulciano in 3D. Virtual models for urban development]. Disegnarecon, 7(1), pp. 1-20. (in Italian) DOI: $10.6092 /$ issn.1828-5961/4152

Bonacini, E., Inzerillo, L., Marcucci, M., Santagati, C., Todisco, F. (2015). 3D \#Digitallnvasions: a crowdsourcing project for mobile user generated content. Furnace Journal, 2. Available at: https://www.researchgate.net/publication/282317653_3D_DigitalInvasions_a_crowdsourcing_project_for_mobile_user_generated_content (viewed on: 12.03.2017)

Levy, P. (1997). I/ Virtuale [Virtuality]. Milan: Cortina Raffaello Publishing House. (in Italian)

Maldonado, T. (2005). Realtà e Virtuale [Reality and virtuality]. Milan: Feltrinelli Publishing House. (in Italian)

Marini, D., Bertolo, M., Rizzi, A. (2006). Comunicazione visiva digitale, Fondamenti di Eidomatica [Visual digital communications. Basics of the computer graphics]. Boston: Pearson: Addison Wesley Publishing House.

Merlo, A., Sánchez Belenguer, C., Vendrell Vidal, E., Fantini, F., Aliperta, A. (2013). 3D model visualization enchancements in real-time game engines. Trento, Italy.

Remondino, F., Rizzi, A., Giorgio, A., Jimenez, B., Menna, F., Nex, F., Baratti, G. (2011). Rilievi e Modellazione 3D [Geodesic surveying and 3D modelling]. In: proceedings of the 15th National Conference ASITA (Italian Federation of Scientific Assosiations in the sphere of regional information). Reggia di Colorno. (in Italian) 